\title{
Touching the didactic contract - a student perspective on intergenerational touch in PE
}

\section{Introduction}

A growing anxiety around intergenerational touch in educational settings has both emerged and increased in recent years. Previous research reveals that Physical Education (PE) teachers have become more cautious in their approaches to students and avoid physical contact or other behaviour that could be regarded as suspicious (Fletcher, 2013; Öhman, 2016; Piper, Garratt, \& Taylor, 2013). Research on intergenerational touch in PE educational settings has predominantly focused on the teacher's perspective. It has shown that the fear of touching is not only a personal dilemma for the teachers, but has also become a pedagogical problem, where the tension between the necessity of using physical contact and the "contemporary discourse which supports a categorical avoidance of touch between adult and child' (Fletcher, 2013, p.701) has become increasingly uncomfortable for teachers of PE. So, what do the students say about physical contact in the teaching situations? Very little at all is known about the views of students, which constitutes a knowledge gap and makes research in this area imperative. This is vital in order to gain a more balanced picture, rather than a one-sided view of intergenerational touch in PE practise. The aim of this article is thus to investigate physical contact between teachers and students in PE from a student perspective, in Sweden.

\section{Methodology}

This study has a didactical framework in order to understand the relationship between teacher, student and content knowledge in relation to intergenerational touch. This framework is based on the Scandinavian didactical research tradition, which is also in line with the French research tradition, and includes research topics such as what is taught and learned, how is it taught and learned, why is it taught and learned and by whom is it taught and learned (Amade-Escot, 2006; Quennerstedt \& Larsson, 2015, p. 567). It is, furthermore the concept of the didactic contract that has been used in the analytical process of this study. This concept was first developed in the school subject of mathematics by Brousseau (1997). The didactic contract can be compared to an agreement between teachers and students about the subject content, where both parties know what to expect from the other, i.e. who is responsible for what in the teaching/learning situation 
specifically concerning the target knowledge (Brousseau, 1997). In this study it is the rules of the didactic contract in relation to physical contact that is of interest.

\section{Participants}

The study draws on interview data collected from 6 focus group interviews, using photo elicitation, involving a total of 18 students during their final year at upper secondary school in Sweden. The students attending the school are generally from white (mainly ethnic Swedes) middle class homes with few social problems. In view of the study's potentially sensitive topic, selecting students on a voluntary basis was regarded as the most ethical strategy. The volunteers were all over the age of 18 and no longer had physical education as a compulsory subject at school. Female and male students were represented. Ethical reflections permeate the study as a whole. As is customary, the participants were briefed about the purpose and method of the study prior to the survey. They were told that participation was voluntary and that confidentiality would be assured.

\section{Results}

One of the study's major findings is that intergenerational touch is purpose bound, i.e. that physical contact is considered relevant if the teacher's intentions (purpose) with the touching are well meant. This is also the major rule in the didactic contract regarding physical contact in PE. The results show that this didactic contract mostly consists of implicit agreements that are acknowledged by both parties, thus making physical contact highly relevant and obvious to the students. However, these agreements are complex and can be breached in several ways, thus making the outcome somewhat uncertain for students and teachers alike.

In the following we present two specific aspects of the didactic contract: (i) Main agreements regarding physical contact and (ii) Main disagreements regarding physical contact.

\section{(i) Main agreements regarding physical contact}

The students very clearly show that they regard physical contact as something obvious and relevant, especially when it is used to support exercises, give comfort or encouragement or to prevent injury. Consequently, when physical contact is viewed as straightforward, taken for 
granted and expected (hoped for) the teachers use of it is purpose bound. One level of the agreement is the practical learning aspect of the purpose bound physical contact. Here, the students specifically talk about the practical elements of physical touch that they find relevant and obvious. For example Johan says:

I think it is very difficult to learn new techniques if you don't have someone who can help you to get a feel for it, so to speak. (Johan, male student)

According to Johan, students regard physical contact as both important and expected when learning a specific technique, so that they get a feel for it. Andrea expresses something similar when describing how she learned to swim:

... then the teacher stood there and like, held onto your feet and demonstrated the movements and... that's how you learned sort of. (Andrea, female student)

It is apparent that for a student to learn new techniques and get the right feel for the movements, physical contact is both necessary and expected. Here too, learning is closely linked to the teacher's use of physical contact. As the students know what to expect and agree on it, the didactic contract is obvious.

There is however also an emotional aspect. Several students argue that children need closeness and encouragement and that this can be accomplished through physical contact in PE. For example one student reflects on spontaneous hugs when scoring a goal. Another example is Idun who reflects on closeness and the importance of this for some students:

Most people need closeness and the teacher is maybe your closest link. Because you don't know what it's like for children at home and such, and then maybe a hug, unwarranted or so, can be good for a child... so you can't just, it's like this also, it is so subtle, because that hug is maybe what makes you get through the day, you know, but there is no... then there is no purpose, but maybe it's not ... I don't know. (Idun, female student) 
Here, Idun articulates the complexity of intergenerational touch. Her quote also serves as an example of situations where the didactic contract is close to being breached. Idun can see that a hug can have a positive effect and be very important to a child who is in need of comfort, support or closeness. She also justifies the hug in this particular context, even though it could be difficult to explain or justify in the PE curriculum and is thus not as obvious in terms of the didactic contract as in the other examples. In this case, the purpose of touch is not connected to the subject content of $\mathrm{PE}$ as such, but to the trait of being human, which is nevertheless part of the didactic contract.

\section{(ii) Main disagreements regarding physical contact}

Sometimes physical contact is viewed as unnecessary and if physical contact is used in these situations the didactic contract would be breached. One of the disagreement aspects is interference from the teacher when the students want to feel capable, which Jonas explains like this:

\footnotetext{
... you want to feel independent, to feel capable... you feel that you can do it yourself without help... you don't want to feel as if you are worse than everyone else. (Jonas, male student)
}

What Jonas expresses here is a willingness to try something on his own, without interference from a teacher. He does not want to be belittled or to feel inferior to anyone else, but wants to be independent. The purpose of physical contact is unclear and could cause the didactic contract to be breached.

Another aspect of a disagreement or breach of the didactic contract is interference from the teacher when physical contact is not required in the activity. In one of the interviews, four girls discuss dodgeball as an activity in which teachers do not usually use physical contact, because there are no special techniques to be learned. Thus, according to the students, using physical contact while instructing dodgeball would breach the didactic contract and consequently feel strange or odd. 
Finally, several students indicate that it is not possible to say precisely that touch is appropriate in one situation and not in another. Rather, it is a matter of personal preference and the teacher being able to read and know their students. For example Jesper says:

It's like this, you know, that what one person thinks is uncomfortable, maybe another doesn't think is uncomfortable, you know. (Jesper, male student)

In other words, the situation or activity does not necessarily determine whether intergenerational touch is viewed as appropriate or inappropriate, but rather depends on who you are as a person. Some students say that if a teacher has to touch a student it must be done in the right way. When asked what the right way is, Elin talks about a teacher she had in the past and concludes by saying:

But it feels as if it is very individual, from person to person, and that you can't really say like, yeah in this situation it's ok for the teacher to touch a student, but not in this, it's more like, that you have to have a communication with the teacher so that you can say: this is ok by me, and this is not ok. (Elin, female student)

Elin shows that communication between teachers and students is very important for building a respectful and trusting relationship.

It is obvious then, that there is not one didactic contract between students and PE teachers that works in the same way for all students at all times, but many. Different didactic contracts can be formed with different students, depending on what they are like as people.

\section{Discussion and conclusion}

The students confirm that for the most part there is an implicit agreement between teacher and student regarding when, how or why physical contact is used in PE. If intergenerational touch is to be considered as a mutual agreement between teacher and student, it has to be purpose bound. When the purpose of physical touch is clear the students support it as a pedagogical tool.

This study has shown that if teachers and students agree or enter some kind of contract that defines what, how and why physical contact is used in PE, the question is not one of appropriate 
or inappropriate touch, but rather that there is an agreement between the people involved about what is expected.

We should not ban intergenerational touch, but rather focus on teachers' abilities to deal professionally with the didactic contract regarding physical contact, which would be important for PE teacher education and in-service training. If the purpose of physical contact was always made clear, this could reduce the tension in the 'touch problem'. 


\section{References}

Amade-Escot, C. (2006). Student learning within the Didactique tradition. In D. Kirk, D. Macdonald, \& M. O'Sullivan (Eds.), The handbook of physical education (pp. 347-365). Trowbridge: Sage Publications.

Brousseau, G. (1997). Theory of didactical situations in mathematics. Balacheff, N., Cooper, M., Sutherland, R. \& Warfield, V. (Eds.). New York, Boston, Dordrecht, London, Moscow: Kluwer Academic Publishers

Fletcher, S. (2013). Touching practice and physical education: deconstruction of a contemporary moral panic. Sport Education and Society, 18:5, 694-709. doi: 10.1080/13573322.2013.774272

Öhman, M. (2016). Losing touch - Teachers' self-regulation in physical education. European Physical Education Review, 1-14. doi: 10.1177/1356336X15622159

Piper, H., Garratt, D. \& Taylor, B. (2013). Child abuse, child protection and defensive 'touch' in PE teaching and sports coaching. Sport, Education and Society, 18:5, 583-598. doi: $10.1080 / 13573322.2012 .735653$

Quennerstedt, M. \& Larsson, H. (2015). Learning movement cultures in physical education practice. Sport Education and Society, 20:5, 565-572. doi: 10.1080/13573322.2014.994490 